\title{
OPEN Eye symptoms in patients with benign thyroid diseases
}

\author{
Nadia Sawicka-Gutaj ${ }^{1}$, Paulina Ziółkowska ${ }^{1,4}$, Klaudia Wojciechowska ${ }^{1,4}$, Sara Shawkat ${ }^{1}$, \\ Agata Czarnywojtek ${ }^{1,2}$, Wojciech Warchoł ${ }^{3}$, Jerzy Sowiński ${ }^{1}$, Ewelina Szczepanek-Parulska ${ }^{1}$ \& \\ Marek Ruchała ${ }^{1}$
}

Thyroid diseases may cause a variety of functional and structural body changes, including eye and vision abnormalities, which can have a negative impact on a patient's well-being. However, only a few studies on the impact of other benign thyroid diseases on the visual process are available in the literature. In this study, using the Polish version of the thyroid-specific quality of life (ThyPROpl) questionnaire, we aimed to determine the self-reported influence of benign thyroid diseases (e.g., nodular goiter, toxic nodular goiter, Graves' disease, thyroid orbitopathy, Hashimoto's thyroiditis, and surgical hypothyroidism) on patients' eyes and vision. This was a prospective study. In total, 374 randomly selected euthyroid patients and 255 control subjects responded to the ThyPROpl questionnaire and the results were evaluated. Nearly $69 \%$ of the respondents reported that the most frequent condition was "reduced sight." Men most often reported wet/tearing eyes (66\%). The occurrence of eyelid sacks or swollen eyelids (64\%), ophthalmalgia (62\%), and eye dryness (61\%) was marked almost as often. In total, $29 \%$ of the patients reported diplopia, and it was found to be most prevalent among those with thyroid orbitopathy. Other complaints were similarly prevalent among all the subgroups. A positive correlation was also observed between the scores of the "eye symptoms" and other ailments. Except for swelling around the lower eyelids, patients with thyroid diseases more frequently experienced all of the ocular complaints analyzed in this study compared with controls. This study showed that eye complaints are common in patients with benign thyroid diseases and ocular disturbances have a negative impact on the overall quality of life of patients.

Thyroid diseases are common endocrine disorders and may cause a variety of functional and structural body changes, including eye and vision abnormalities, which have a negative impact on a patient's well-being ${ }^{1,2}$.

Thyroid-associated ophthalmopathy (TAO) — also known as thyroid eye disease, Graves' orbitopathy, or Graves' ophthalmopathy (GO) - is an inflammatory disease of the eye and orbital tissues ${ }^{2}$ and is reported to be one of the most common causes of ocular myopathy in adults. Generally, TAO is associated with Graves' disease; however, regardless of the thyroid function, it may also occur in patients with chronic lymphocytic thyroiditis (Hashimoto's disease) $^{3,4}$. The clinical signs and symptoms characteristic of TAO are double vision, proptosis, lid retraction, restrictive extraocular myopathy, optic neuropathy, and inflammatory ocular surface disorders. However, as the pathogenesis of TAO is not fully understood, the therapeutic options are limited ${ }^{5-8}$.

TAO is rarely reported and is less $\mathrm{known}^{3,9}$ in the case of chronic lymphocytic thyroiditis or Hashimoto's disease. Moreover, patients with Hashimoto's disease may develop eye changes similar to those observed in patients with TAO, such as symptoms related to dry eye syndrome. These symptoms cause serious discomforts such as dryness, burning, grittiness, and eye irritation that increase during the daytime ${ }^{3}$. If dry eye syndrome-related symptoms are left untreated, then they may damage the eyes, thereby resulting in vision impairment or rarely in the loss of vision ${ }^{10,11}$. These changes when occur in long term lead to mood or sleep disorders ${ }^{1,12}$. It should also be emphasized that some clinical conditions may mimic TAO and, therefore, each patient with a suspicion of TAO should be differentially diagnosed to rule out non-thyroid etiology $y^{13,14}$.

Nearly $80 \%$ of all sensory processing that occurs in the body is directly related to the information that is transmitted from the eyes to the brain. Therefore, any impairment in vision can lead to functional disability and greatly affect an individual's personal and social behavior ${ }^{15,16}$. Numerous studies have confirmed that TAO can cause a significant decrease in the quality of life $(\mathrm{Q} o \mathrm{~L})$, and thyroid dysfunction leads to further worsening of

\footnotetext{
${ }^{1}$ Department of Endocrinology, Metabolism and Internal Medicine, Poznan University of Medical Sciences, 49 Przybyszewskiego St., 60-355 Poznan, Poland. ${ }^{2}$ Department of Pharmacology, Poznan University of Medical Sciences, Poznan, Poland. ${ }^{3}$ Department of Ophthalmology and Optometry, Poznan University of Medical Sciences, Poznan, Poland. ${ }^{4}$ These authors contributed equally: Paulina Ziółkowska and Klaudia Wojciechowska. ${ }^{\square}$ email: nsawicka@ump.edu.pl
} 
a patient's well-being. However, only a few studies on the impact of other benign thyroid diseases on the visual process are available in the literature. Further, the objective methods used for an eye examination often differ based on an individual's perception and self-esteem-the factors that affect the daily life of an individual the most. Therefore, in this study, using the Polish version of the thyroid-specific QoL (ThyPROpl) questionnaire, we aimed to determine the self-reported influence of benign thyroid diseases on the eyes and vision of patients ${ }^{17}$. We analyzed the eye symptoms reported by patients in euthyroid state and assessed the potential relationship between the reported complaints and the overall QoL-clinical as well as biochemical parameters. We also compared the responses of the patients with those of the control group (adults with no history of thyroid disease).

\section{Patients and methods}

This was a prospective study. In total, 374 euthyroid patients with benign thyroid diseases were randomly selected from the Department of Endocrinology, Metabolism and Internal Diseases, and outpatient clinic of the Clinical Hospital of the Poznan University of Medical Sciences. They were asked to complete the ThyPROpl questionnaire, and the results were examined. Each patient participating in the study was assigned to one of the following six subgroups in order to examine the subjective feelings and differences between patients struggling with various thyroid problems: 1, nodular goiter; 2, toxic nodular goiter; 3, Graves' disease; 4, thyroid orbitopathy; 5 , chronic lymphocytic thyroiditis; and 6, surgical hypothyroidism. Exclusion criteria were the presence of other chronic diseases, including type 2 diabetes, hypertension, other autoimmune diseases, or cancers potentially affecting vision and QoL. Laboratory tests (TSH, thyroid-stimulating hormone; fT3, free triiodothyronine; fT4, free thyroxine; TRAb, TSH-receptor antibodies; TPOAb, anti-thyroperoxidase antibodies; TgAb, thyroglobulin antibodies) were performed on the same day. Each patient underwent a physical examination. Patients with thyroid orbitopathy underwent an ophthalmological consultation and had a magnetic resonance imaging of orbits. Patients with hypothyroidism were treated with levothyroxine, while those with hyperthyroidism (e.g., Graves' disease and toxic nodular goiter) were treated with thiamazole. The control group consisted of 255 healthy people and answered questions from the nine scales of ThyPRO questionnaire without specific attribution to thyroid disease. In addition, sociodemographic data were collected from all the respondents and TSH levels were reported by healthy participants.

ThyPRO is a validated thyroid-specific QoL questionnaire ${ }^{18,19}$. We used its Polish version (ThyPROpl), which was developed according to the standard methodology used for the translation of patient-reported outcomes ${ }^{17}$. It contains 85 questions summarized in 13 scales, measuring various aspects of QoL. Patients are asked to mark their answers on the five-point Likert scale: 0 , not at all; 1 , a bit; 2 , on average; 3 , quite strongly; and 4 , very much. The reference period is 4 weeks. If more than half of the questions on the scale are answered, then the number of points is divided by the total maximum number for the subscale as a whole and the obtained result is linearly transformed into a scale of $0-100$.

The domain assessing eye symptoms and vision disorders includes the following eight questions about visual problems that are often associated with thyroid diseases:

- Have you had wet or tearing eyes?

- Have you had bags under your eyes or swollen eyelids?

- Did you have a feeling of dryness or a feeling of sand under the eyelids?

- Have you had eye problems?

- Have you felt pressure within (or behind) the eyeballs?

- Have you had double vision?

- Did your eyes ache?

- Have you felt hypersensitivity to light?

Ethics. The study was approved by the Ethical Committee of Poznan University of Medical Sciences, and all patients signed informed consent to participate in the study. All the methods used in the study were performed in accordance with the relevant guidelines and regulations.

Statistical analysis. Statistical analysis was performed using the Statistica program (universal system for statistical data analysis, version 13.1). The results between men and women were compared using the MannWhitney test. The analyzed parameters were compared between all groups using the ANOVA/Kruskal-Wallis test, and the responses of study subgroups and healthy controls were compared using Fisher's exact test. The Shapiro-Wilk test was applied to investigate the normality of data distribution. Therefore, the data did not follow a normal distribution, and were presented as medians and as lower and upper quartiles (Tables 1,2). Potential correlations between the parameters were assessed by Spearman's $R$ test. A $p$-value less than or equal to 0.05 was considered statistically significant.

\section{Results}

Study subjects. The study involved 374 patients, $81 \%$ of whom were women. Clinical data are provided in Table 1.

Figure 1 shows the prevalence of individual ocular complaints in male and female patients. The most frequently reported condition by the patients was "reduced sight" - as many as $69 \%$ of respondents received a score equal to or greater than 1 point on the Likert scale. Nearly $66 \%$ of the men reported wet/tearing eyes most often. The patients also frequently reported the occurrence of eyelid sacks or swollen eyelids (64\%), ophthalmalgia (62\%), and eye dryness (61\%). However, they less likely experienced double vision, but still, nearly one-third of 


\begin{tabular}{|l|l|l|l|l|}
\hline & Number of available data $(\mathbf{N})$ & Percentage of available data $(\%)$ & Median & IQR \\
\hline Men/women & $70 / 304$ & $19 / 81$ & - & - \\
\hline Age, years & 292 & 78 & 50.0 & $39-64$ \\
\hline TSH, mIU/L & 280 & 75 & 0.6 & $0.1-1.6$ \\
\hline fT3, pmol/L & 151 & 40 & 5.0 & $4.1-5.0$ \\
\hline fT4, pmol/L & 206 & 55 & 17.0 & $14.3-20.1$ \\
\hline TRAb, IU/L & 56 & 15 & 1.2 & $0.3-4.3$ \\
\hline TPOAb, IU/ml & 100 & 27 & 22.0 & $8.0-105.5$ \\
\hline TgAb, IU/ml & 82 & 22 & 35.5 & $10.0-64.0$ \\
\hline
\end{tabular}

Table 1. Clinical data and laboratory test results of patients participating in the study. $f T 3$ free triiodothyronine, $f T 4$ free thyroxine, IQR interquartile range, $N$ the number of valid answers, $T g A b$ thyroglobulin antibodies, TPOA $b$ anti-thyroperoxidase antibodies, TRA $b$ TSH-receptor antibodies, TSH thyroid-stimulating hormone.

\begin{tabular}{|l|l|l|c|}
\hline Diagnosis & N (\%) & Median & IQR \\
\hline Nodular goiter & $81(22)$ & 16 & $9-38$ \\
\hline Toxic nodular goiter & $74(20)$ & 21 & $9-34$ \\
\hline Graves' disease & $60(16)$ & 25 & $9-44$ \\
\hline Thyroid orbitopathy & $12(3)$ & 66 & $22-78$ \\
\hline Chronic lymphocytic thyroiditis & $67(18)$ & 19 & $9-38$ \\
\hline Surgical hypothyroidism & $78(21)$ & 19 & $9-38$ \\
\hline
\end{tabular}

Table 2. Response of patients with benign thyroid diseases to the "eye symptoms" section of the ThyPROpl questionnaire. $I Q R$ interquartile range, $N$ the number of valid answers.

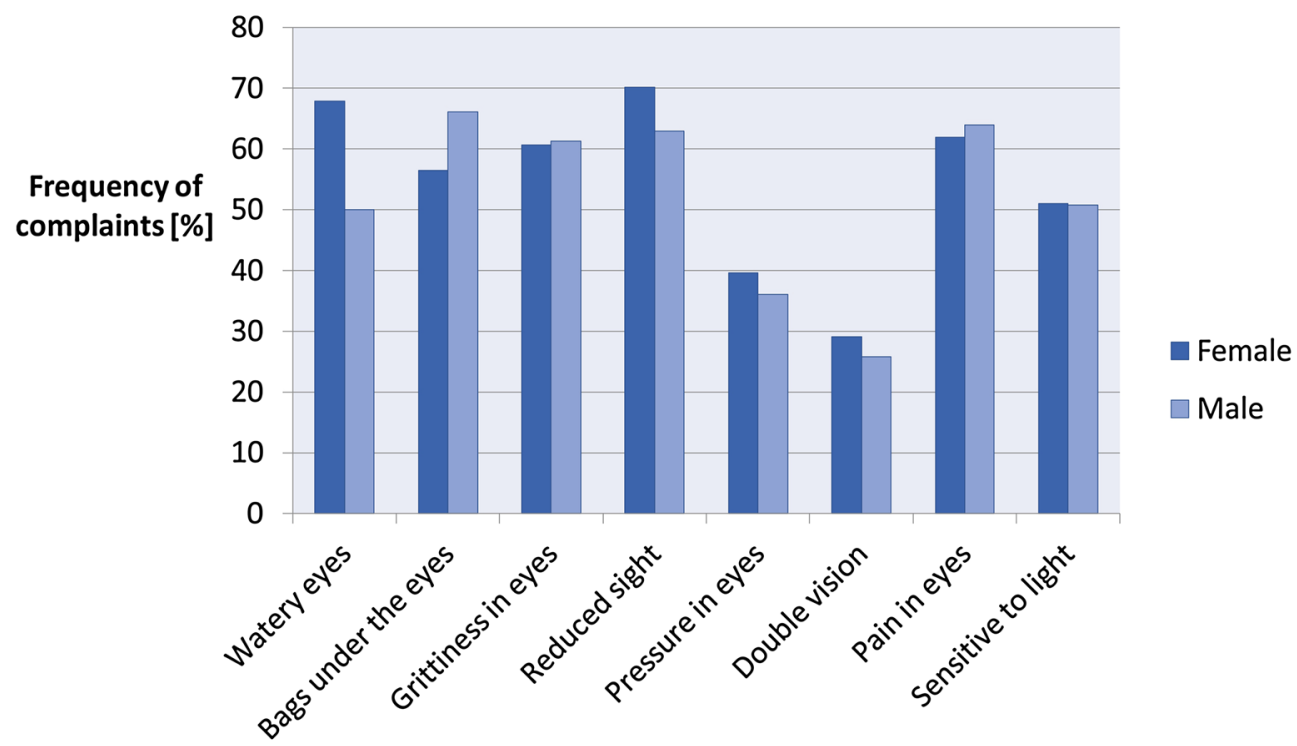

Figure 1. The prevalence of eye symptoms in patients with thyroid diseases based on the results of ThyPROpl questionnaire among women and men.

them reported diplopia (29\%). For individual questions, the differences in results did not exceed 10 percentage points for both men and women.

Patients from each of the six study groups had similar TSH concentrations $(p=0.1368)$, but they showed differences in the levels of thyroid autoantibodies (TRAb: $p=0.0004$, TPOAb: $p=0.003$, TgAb: $p=0.0009$ ). Patients with Graves' disease and thyroid orbitopathy had the highest levels of TRAb, while patients with chronic lymphocytic thyroiditis and surgical hypothyroidism had higher levels of TPOAb. 


\begin{tabular}{|l|l|l|c|}
\hline A pair of variables & $\mathbf{N}$ & $\boldsymbol{R}$ Spearman & $\boldsymbol{p}$-value \\
\hline Eye symptoms and cognitive complaints & 371 & 0.49 & $<0.0000001$ \\
\hline Eye symptoms and anxiety & 370 & 0.45 & $<0.0000001$ \\
\hline Eye symptoms and depressivity & 368 & 0.39 & $<0.0000001$ \\
\hline Eye symptoms and impaired social life & 372 & 0.36 & $<0.0000001$ \\
\hline Eye symptoms and impaired daily life & 369 & 0.42 & $<0.0000001$ \\
\hline Eye symptoms and cosmetic complaints & 369 & 0.46 & $<0.0000001$ \\
\hline Eye symptoms and overall quality of life & 364 & 0.40 & $<0.0000001$ \\
\hline
\end{tabular}

Table 3. Results of the correlation of scores of "eye symptoms" section with other scales of ThyPROpl questionnaire (sugerowane usunięcie - wg recenzenta nie pasuje do koncepcji artykułu). $N$ the number of valid answers, $R$ Spearman Spearman's $R$ test result.

\begin{tabular}{|c|c|c|c|c|c|c|c|}
\hline Study group & $\begin{array}{l}\text { Nodular goiter } \mathrm{N} \\
(\mathbf{8 1})\end{array}$ & $\begin{array}{l}\text { Toxic nodular goiter } \\
\text { N (74) }\end{array}$ & $\begin{array}{l}\text { Graves' disease N } \\
(60)\end{array}$ & $\begin{array}{l}\text { Thyroid orbitopathy } \\
\text { N (12) }\end{array}$ & $\begin{array}{l}\text { Chronic lymphocytic } \\
\text { thyroiditis } \mathrm{N}(67)\end{array}$ & $\begin{array}{l}\text { Surgical } \\
\text { hypothyroidism } \\
\mathrm{N}(78)\end{array}$ & Controls \\
\hline $\begin{array}{l}\text { Watery eyes, } \mathrm{N}(\%) \\
p\end{array}$ & $\begin{array}{l}42(52.5) \\
p=0.002\end{array}$ & $\begin{array}{l}47(63.5) \\
p=0.000006\end{array}$ & $\begin{array}{l}40(66.7) \\
p=0.000004\end{array}$ & $\begin{array}{l}10(90.9) \\
p=0.0002\end{array}$ & $\begin{array}{l}35(52.2) \\
p=0.007\end{array}$ & $\begin{array}{l}39(51.3) \\
p=0.007\end{array}$ & $85(33.3)$ \\
\hline $\begin{array}{l}\text { Bags under the eyes, } \\
\text { N (\%) } \\
p\end{array}$ & $\begin{array}{l}47(60.3) \\
p=0.157\end{array}$ & $\begin{array}{l}44(59.5) \\
p=0.234\end{array}$ & $\begin{array}{l}43(71.7) \\
p=0.004\end{array}$ & $\begin{array}{l}9(81.8) \\
p=0.063\end{array}$ & $\begin{array}{l}45(67.2) \\
p=0.019\end{array}$ & $\begin{array}{l}48(62.3) \\
p=0.090\end{array}$ & $130(51)$ \\
\hline $\begin{array}{l}\text { Grittiness in eye, } \\
N(\%) \\
p\end{array}$ & $\begin{array}{l}47(58.8) \\
p=0.007\end{array}$ & $\begin{array}{l}47(63.5) \\
p=0.0008\end{array}$ & $\begin{array}{l}39(66.1) \\
p=0.0005\end{array}$ & $\begin{array}{l}9(81.8) \\
p=0.010\end{array}$ & $\begin{array}{l}37(55.2) \\
p=0.038\end{array}$ & $\begin{array}{l}43(56.6) \\
p=0.018\end{array}$ & $104(40.8)$ \\
\hline $\begin{array}{l}\text { Reduced sight, N (\%) } \\
p\end{array}$ & $\begin{array}{l}54(67.5) \\
p<0.000001\end{array}$ & $\begin{array}{l}49(66.2) \\
p<0.000001\end{array}$ & $\begin{array}{l}40(66.7) \\
p<0.000001\end{array}$ & $\begin{array}{l}8(72.7) \\
p=0.005\end{array}$ & $\begin{array}{l}45(68.2) \\
p<0.000001\end{array}$ & $\begin{array}{l}56(73.7) \\
p<0.000001\end{array}$ & $76(29.9)$ \\
\hline $\begin{array}{l}\text { Pressure in eyes, } \\
\mathrm{N}(\%) \\
p\end{array}$ & $\begin{array}{l}25(30.9) \\
p=0.003\end{array}$ & $\begin{array}{l}27(37.5) \\
p=0.0001\end{array}$ & $\begin{array}{l}26(44.1) \\
p=0.000004\end{array}$ & $\begin{array}{l}7(70) \\
p=0.0002\end{array}$ & $\begin{array}{l}29(43.9) \\
p=0.000002\end{array}$ & $\begin{array}{l}28(36.8) \\
p=0.0001\end{array}$ & $39(15.3)$ \\
\hline $\begin{array}{l}\text { Double vision, } \mathrm{N}(\%) \\
p\end{array}$ & $\begin{array}{l}20(25) \\
p=0.001\end{array}$ & $\begin{array}{l}17(23.3) \\
p=0.0006\end{array}$ & $\begin{array}{l}23(38.3) \\
p<0.000001\end{array}$ & $\begin{array}{l}9(81.8) \\
p<0.000001\end{array}$ & $\begin{array}{l}20(30.3) \\
p=0.000007\end{array}$ & $\begin{array}{l}17(22.1) \\
p=0.001\end{array}$ & $20(7.8)$ \\
\hline $\begin{array}{l}\text { Pain in eyes, } \mathrm{N}(\%) \\
p\end{array}$ & $\begin{array}{l}44(55) \\
p=0.014\end{array}$ & $\begin{array}{l}46(63) \\
p=0.0003\end{array}$ & $\begin{array}{l}41(68.3) \\
p=0.00004\end{array}$ & $\begin{array}{l}8(72.7) \\
p=0.031\end{array}$ & $\begin{array}{l}41(62.1) \\
p=0.0008\end{array}$ & $\begin{array}{l}46(60.5) \\
p=0.001\end{array}$ & $99(38.8)$ \\
\hline $\begin{array}{l}\text { Sensitive to light, } \\
\mathrm{N}(\%) \\
p\end{array}$ & $\begin{array}{l}37(47.4) \\
p=0.0002\end{array}$ & $\begin{array}{l}33(45.8) \\
p=0.0007\end{array}$ & $\begin{array}{l}36(62.1) \\
p<0.000001\end{array}$ & $\begin{array}{l}9(81.8) \\
p=0.0002\end{array}$ & $\begin{array}{l}34(52.3) \\
p=0.00003\end{array}$ & $\begin{array}{l}36(47.4) \\
p=0.0003\end{array}$ & $63(24.7)$ \\
\hline
\end{tabular}

Table 4. Comparison of prevalence of particular ocular complaints between patients with thyroid disorders and healthy controls. $N$ number of patients, $p$, $p$-value.

Table 2 shows the scores of eye domain for each subgroup. Patients with thyroid orbitopathy showed the highest percentage of vision problems. In addition, patients with thyroid orbitopathy (subgroup 4), nodular goiter, and toxic nodular goiter responded differently to ocular symptoms, which was statistically significant, as well as patients with chronic lymphocytic thyroiditis and surgical hypothyroidism (subgroups 1, 2, 5, and 6). In the case of subgroup 3 (Graves' disease), the difference was not statistically significant.

The responses of patients to specific questions in the section "ocular complaints" were also compared between subgroups. Patients with thyroid orbitopathy more frequently reported double vision $(p=0.0018)$, while other complaints were similarly prevalent among all subgroups.

The results showed a positive relationship between the scores of the "eye symptoms" scale and the results of all other domains of the ThyPROpl questionnaire (Table 3).

The results showed no correlations between the scores of the "eye symptoms" scale, antibodies (TRAb, TgAb, $\mathrm{TPOAb}), \mathrm{TSH}, \mathrm{fT} 3, \mathrm{fT} 4$, and the age of the subjects in all the groups $(p>0.05)$.In addition, further analyses among subgroups did not show any correlations between the parameters analyzed and eye complaints $(p>0.05)$. Eye symptoms, cognitive complaints, and daily life scores were found to be similar for both men and women.

General population sample. A total of 255 healthy people (207 women and 48 men) returned a completed ThyPROpl questionnaire. The median age of the control group was 54 years (interquartile range: 44.360.7 years). The sex distribution and age of the control group resembled those of patients with thyroid disorders ( $p=0.5639$ and $p=0.3983$, respectively). The mean TSH concentrations were $1.77 \pm 0.75 \mu \mathrm{IU} / \mathrm{ml}$. Nearly $51 \%$ of the healthy controls most frequently reported "bags under the eyes," while only $7.8 \%$ reported double vision. The comparison of results obtained revealed that patients with thyroid diseases more frequently experienced all of the ocular complaints analyzed in this study, except swelling around the lower eyelids, which was more common in patients with Graves' disease and chronic lymphocytic thyroiditis. The results obtained are given in Table 4. 


\section{Discussion}

This study, using the ThyPROpl questionnaire, aimed to analyze the self-reported thyroid-related ocular complaints by patients with benign thyroid diseases and the impact of these diseases on patients' QoL. Generally, eye changes are usually associated with Graves' disease; therefore, previous studies that analyzed ocular symptoms in thyroid diseases mainly focused on patients with Graves' disease and Graves' orbitopathy ${ }^{20}$. The novelty of our study was that we investigated and compared ocular complaints reported by patients with various benign thyroid diseases in the euthyroid state. Therefore, the ThyPROpl questionnaire proved to be an effective tool for us. ThyPROpl questionnaire helped us to explore the patients' perception and self-esteem, which particularly affected their QoL. Furthermore, we compared our results with a sex- and age-matched healthy control group.

Both generic and disease-specific questionnaires showed significant worsening of well-being in patients with Graves' orbitopathy ${ }^{21-23}$. Furthermore, patients with thyroid dysfunctions, chronic lymphocytic thyroiditis, and nodular goiter showed a decrease in QoL ${ }^{24-26}$. However, in patients with benign thyroid disorders, surgical treatment or therapy aiming to restore thyroid function showed a beneficial impact on the QoL, but in some patients, it did not show any normalization in the patient-reported well-being even after several years of diagnosis ${ }^{27-29}$.

We observed that visual complaints are common in patients with benign thyroid diseases, which affect the various aspects of vision. Nearly $70 \%$ of patients with thyroid disease experienced eye problems, which may be interpreted as a decrease in visual acuity, but they also experienced other impairments such as cosmetic abnormalities. Of the eight complaints included in this study, as many as six were reported by more than half of the patients, and this shows that they should be referred to an ophthalmologist or optometrist for an accurate diagnosis. Almost equally often, patients reported swelling around their lower eyelids, grittiness, and pain in the eyes. Over $50 \%$ of patients also reported watery eyes (the most common ailment among men and patients with orbitopathy) and photosensitivity. These complaints may indicate dry eye syndrome, which is described as the most common cause of discomfort in TAO, and up to $85 \%$ of patients reported that they had dry eye syndrome. Moreover, the prevalence of ocular complaints was significantly higher in patients with thyroid diseases than in the general population.

It is difficult to determine whether thyroid-attributed ocular complaints experienced by patients are indeed caused by thyroid diseases. To some extent, autoimmune pathogenesis underlying Graves' disease and chronic lymphocytic thyroiditis may explain the ocular and vision impairment reported by the patients; however, it is relatively difficult to explain the common eye changes experienced by patients with nodular goiter. Studies that have analyzed visual disturbances associated with thyroid nodular disease are scarce. However, in studies that have focused on the QoL of patients with Graves' disease and toxic nodular goiter, patients with toxic nodular goiter, for unknown reasons, also experienced "eye Symptoms" ${ }^{23}$. The authors deliberated whether these results were directly related to thyroid disease or not. However, immunological markers that might be involved in the development of nodular goiter may explain the eye symptoms in those patients ${ }^{30}$.

Certainly, future research should focus on discovering specific mechanisms linking eyes symptoms and thyroid immunogenicity.

The prevalence of individual complaints was observed to be different in patient subgroups. As suspected, patients with Graves' orbitopathy frequently complained of problems. Patients with Graves' disease and chronic lymphocytic thyroiditis also complained frequently, which may suggest the role of ongoing autoimmune processes or unrecognized mild orbitopathy in these groups. Although thyrotropin receptors act as primary autoantigens in the pathogenesis of TAO in patients with Graves' disease, TRAbs are not observed in patients with chronic lymphocytic thyroiditis ${ }^{8}$. However, in chronic lymphocytic thyroiditis, antibodies specific to ocular muscle antigens, namely calsequestrin, collagen XIII, flavoprotein, and protein G2s, may occur ${ }^{31-33}$.

Differences in the response of patients in subgroups to "ocular complaints" and differences in the results of laboratory tests were examined. The results revealed no differences in responses between the six subgroups with regard to all ailments except for double vision, which was mainly reported by patients with Graves' orbitopathy. Double vision, which involves oculomotor muscles, was the least reported complaint; however, every third patient was bothered by double vision. This might suggest that in a significant proportion of patients with Graves' disease, orbitopathy was misdiagnosed. Another explanation for the relatively high prevalence of self-reported double vision might be the fact that patients incorrectly used this term.

Further, in this study, the potential relationships between the reported complaints and thyroid metabolism were analyzed. Because euthyroidism was an inclusion criterion, no statistically significant differences in TSH were observed between the subgroups, but antibody tests showed significant differences. Also, no correlation between the results of laboratory tests, age of the subjects, and responses to the "ocular complaints" scale was observed. Moreover, a correlation was observed between the scale outcomes and TRAb levels. Previous studies have shown a negative correlation between TPOAb, TgAb, and QoL ${ }^{34-36}$. In addition, TSH concentration was identified to be an important factor affecting the QoL of GO patients ${ }^{37,38}$. The results of GO-QoL questionnaire showed that younger patients had significantly better cognitive functioning and daily life ${ }^{25}$. However, elderly patients had significantly fewer complaints with regard to appearance (cosmetics), which also contributes toward QoL impairment ${ }^{39}$. Furthermore, young Taiwanese adults showed lower scores on the scale with regard to appearance $^{40}$.

This study showed no statistically significant differences between the responses of men and women to the questionnaires. However, to date, it has been demonstrated that gender has a significant effect on the well-being of a patient with thyroid diseases. Studies have been conducted in different populations, which may also be relevant. For example, Ponto et al. and Riguetto et al. showed better QoL in male patients, whereas Lin et al. showed better QoL in female patients ${ }^{22,25,40}$. The results obtained by these authors and the results obtained by us in this study with regard to the effects of gender on the well-being of patients with thyroid diseases indicate that there may be large discrepancies in this parameter in individual studies. 
We have also proved that the patients' overall QoL was negatively affected by ocular complaints. A correlation study showed a positive relationship between the scores of the "ocular complaints" scale and those of the remaining symptoms mentioned in the questionnaire, such as depression and anxiety, disorders in everyday and social life, cognitive disorders, cosmetic complaints, and general QoL. This means that subjective visual disturbances worsen the QoL of patients, and solving such visual problems could improve their well-being ${ }^{2}$.

It would be worthwhile if the survey is reconducted by applying appropriate ophthalmic and optometric tests and adequate sources (e.g., spherical or prismatic glasses and moisturizing drops) to improve vision. This would allow examining the impact of nonsurgical methods in improving the patients' QoL with regard to comfort and vision function ${ }^{41}$.

\section{Conclusions}

The results of this study demonstrate that eye complaints in patients with benign thyroid diseases are common and that they affect the overall QoL of the patients. So, a multidisciplinary approach that comprises an endocrinologist, an ophthalmologist, an optometrist, and a psychologist is necessary for patients with thyroid diseases to identify co-existing ocular problems and implement appropriate therapy.

Received: 5 June 2021; Accepted: 6 September 2021

Published online: 21 September 2021

\section{References}

1. Watt, T. et al. Quality of life in patients with benign thyroid disorders. A review. Eur. J. Endocrinol. 154, 501-510. https://doi.org/ 10.1530/eje.1.02124 (2006).

2. Kuriyan, A. E., Phipps, R. P. \& Feldon, S. E. The eye and thyroid disease. Curr. Opin. Ophthalmol. 19, 499-506. https://doi.org/10. 1097/ICU.0b013e3283131557 (2008)

3. Tjiang, H., Lahooti, H., McCorquodale, T., Parmar, K. R. \& Wall, J. R. Eye and eyelid abnormalities are common in patients with Hashimoto’s thyroiditis. Thyroid 20, 287-290. https://doi.org/10.1089/thy.2009.0199 (2010).

4. Kahaly, G. J. et al. Thyroid stimulating antibodies are highly prevalent in Hashimoto's thyroiditis and associated Orbitopathy. J. Clin. Endocrinol. Metab. 101, 1998-2004. https://doi.org/10.1210/jc.2016-1220 (2016).

5. Ruchala, M. \& Sawicka-Gutaj, N. Advances in the pharmacological treatment of Graves orbitopathy. Expert. Rev. Clin. Pharmacol. 9, 981-989. https://doi.org/10.1586/17512433.2016.1165606 (2016).

6. Sawicka-Gutaj, N. et al. Nicotinamide phosphoribosyltransferase leukocyte overexpression in Graves opthalmopathy. Endocrine 53, 497-504. https://doi.org/10.1007/s12020-015-0855-8 (2016).

7. Sawicka-Gutaj, N. et al. Changes of nicotinamide phosphoribosyltransferase expressions in thyroid glands of patients with different thyroid pathologies. Biomed. Res. Int. https://doi.org/10.1155/2018/1316390 (2018).

8. Taylor, P. N. et al. New insights into the pathogenesis and nonsurgical management of Graves orbitopathy. Nat. Rev. Endocrinol. 16, 104-116. https://doi.org/10.1038/s41574-019-0305-4 (2019).

9. Cyranska-Chyrek, E. et al. Severe unilateral orbitopathy in a patient with Hashimoto thyroiditis-a case report. BMC Ophthalmol. 19, 1-7. https://doi.org/10.1186/s12886-018-1018-5 (2019).

10. Szczapa-Jagustyn, J., Gotz-Wieckowska, A. \& Kociecki, J. An update on thyroid-associated ophthalmopathy in children and adolescents. J. Pediatr. Endocrinol. Metab. 29, 1115-1122. https://doi.org/10.1515/jpem-2016-0122 (2016).

11. Kan, E., Kilickan, E., Gi, E., Beyazyildiz, E. \& Colak, R. Presence of dry eye in patients with Hashimoto thyroiditis. J. Ophthalmol. https://doi.org/10.1155/2014/754923 (2014).

12. Hatt, S. R., Leske, D. A., Liebermann, L. \& Holmes, J. M. Successful treatment of diplopia with prism improves health-related quality of life. Am. J. Ophthalmol. 157, 1209-1213. https://doi.org/10.1016/j.ajo.2014.02.033 (2014).

13. Boddu, N., Jumani, M., Wadhwa, V., Bajaj, G. \& Faas, F. Not all orbitopathy is Graves: Discussion of cases and review of literature. Front. Endocrinol. 8, 184. https://doi.org/10.3389/fendo.2017.00184 (2017).

14. Ruchala, M., Szczepanek, E., Puszczewicz, M., Sosnowski, P. \& Sowinski, J. Not a graves'situation. Am. J. Med. 124, 210-214. https://doi.org/10.1016/j.amjmed.2010.11.006 (2011).

15. Sah, S. P., Sharma, I. P., Chaudhry, M. \& Saikia, M. Health-related quality of life (HRQoL) in young adults with strabismus in India. J. Clin. Diagn. Res. JCDR 11, NC01. https://doi.org/10.7860/JCDR/2017/24541.9389 (2017).

16. McClure, T. M. et al. The impact of eyeglasses on vision-related quality of life in American Indian/Alaska Natives. Am. J. Ophthalmol. 151(175-182), e172. https://doi.org/10.1016/j.ajo.2010.06.043 (2011).

17. Sawicka-Gutaj, N. et al. ThyPROpl - The Polish version of the thyroid-specific quality of life questionnaire ThyPRO. Endokrynol. Pol. 66, 367-380. https://doi.org/10.5603/EP.2015.0047 (2015).

18. Watt, T. et al. Validity and reliability of the novel thyroid-specific quality of life questionnaire, ThyPRO. Eur. J. Endocrinol. 162, 161-167. https://doi.org/10.1530/EJE-09-0521 (2010).

19. Watt, T. et al. The thyroid-related quality of life measure ThyPRO has good responsiveness and ability to detect relevant treatment effects. J. Clin. Endocrinol. Metab. 99, 3708-3717. https://doi.org/10.1210/jc.2014-1322 (2014).

20. Bartalena, L. et al. The 2016 European thyroid association/European group on Graves' Orbitopathy guidelines for the Management of Graves' Orbitopathy. Eur. Thyroid J. 5, 9-26. https://doi.org/10.1159/000443828 (2016).

21. Wiersinga, W. M. \& Kahaly, G. Graves' Orbitopathy: A Multidisciplinary Approach (Karger Medical and Scientific Publishers, 2007).

22. Ponto, K. A. et al. Quality of life in a german graves orbitopathy population. Am. J. Ophthalmol. 152(483-490), e481. https://doi. org/10.1016/j.ajo.2011.02.018 (2011).

23. Bruscolini, A. et al. Quality of life and neuropsychiatric disorders in patients with Graves' orbitopathy: Current concepts. Autoimmun. Rev. 17, 639-643. https://doi.org/10.1016/j.autrev.2017.12.012 (2018).

24. Winther, K. H. et al. Disease-specific as well as generic quality of life is widely impacted in autoimmune hypothyroidism and improves during the first six months of levothyroxine therapy. PLOS ONE 11, e0156925. https://doi.org/10.1371/journal.pone. 0156925 (2016).

25. Riguetto, C. M., Neto, A. M., Tambascia, M. A. N. \& Zantut-Wittmann, D. E. The relationship between quality of life, cognition, and thyroid status in Graves disease. Endocrine 63, 87-93. https://doi.org/10.1007/s12020-018-1733-y (2019).

26. Sorensen, J. R. et al. Quality of life after thyroidectomy in patients with nontoxic nodular goiter: A prospective cohort study. Head Neck 39, 2232-2240. https://doi.org/10.1002/hed.24886 (2017).

27. Sawicka-Gutaj, N. et al. Patients with benign thyroid diseases experience an impaired sex life. Thyroid 28, 1261-1269. https://doi. org/10.1089/thy.2017.0602 (2018).

28. Sawicka-Gutaj, N. et al. Recurrent goiter: Risk factors, patient quality of life, and efficacy of radioiodine therapy. Pol. Arch. Intern. Med. 129, 22-27. https://doi.org/10.20452/pamw.4383 (2019). 
29. Torring, O. et al. Impaired quality of life after radioiodine therapy compared to antithyroid drugs or surgical treatment for Graves' hyperthyroidism: A long-term follow-up with the thyroid-related patient-reported outcome questionnaire and 36-item short form health status survey. Thyroid 29, 322-331. https://doi.org/10.1089/thy.2018.0315 (2019).

30. Provatopoulou, X. et al. Interleukins as markers of inflammation in malignant and benign thyroid disease. Inflamm. Res. 63, 667-674. https://doi.org/10.1007/s00011-014-0739-z (2014).

31. Gopinath, B., Adams, C.-L., Musselman, R., Tani, J. \& Wall, J. R. Antibodies against calsequestrin and type XIII collagen are good markers for chronic upper eyelid retraction. Ocul. Immunol. Inflamm. 15, 81-88. https://doi.org/10.1080/09273940701299362 (2007).

32. Novak, P. \& Soukup, T. Calsequestrin distribution, structure and function, its role in normal and pathological situations and the effect of thyroid hormones. Physiol. Res. 60, 439. https://doi.org/10.33549/physiolres.931989 (2011).

33. Lahooti, H., Parmar, K. R. \& Wall, J. R. Pathogenesis of thyroid-associated ophthalmopathy: Does autoimmunity against calsequestrin and collagen XIII play a role?. Clin. Ophthalmol. 4, 417. https://doi.org/10.2147/opth.s6534 (2010).

34. Djurovic, M. et al. Cognitive functioning and quality of life in patients with Hashimoto thyroiditis on long-term levothyroxine replacement. Endocrine 62, 136-143. https://doi.org/10.1007/s12020-018-1649-6 (2018).

35. Zivaljevic, V. R. et al. Quality of life improvement in patients with Hashimoto thyroiditis and other goiters after surgery: A prospective cohort study. Int. J. Surg. 21, 150-155. https://doi.org/10.1016/j.ijsu.2015.08.001 (2015).

36. Uysal, H. B. \& Ayhan, M. Autoimmunity affects health-related quality of life in patients with Hashimoto's thyroiditis. Kaohsiung J. Med. Sci. 32, 427-433. https://doi.org/10.1016/j.kjms.2016.06.006 (2016).

37. Abraham-Nordling, M., Wallin, G., Lundell, G. \& Torring, O. Thyroid hormone state and quality of life at long-term follow-up after randomized treatment of Graves disease. Eur. J. Endocrinol. 156, 173-179. https://doi.org/10.1530/eje.1.02336 (2007).

38. Weng, C. et al. Evaluation of quality of life in patients with graves orbitopathy and its influencing factors. Zhonghua Nei Ke Za Zhi 58, 577-583. https://doi.org/10.3760/cma.j.issn.0578-1426.2019.08.006 (2019).

39. Bukvic, B. R. et al. Improvement of quality of life in patients with benign goiter after surgical treatment. Langenbecks Arch. Surg. 399, 755-764. https://doi.org/10.1007/s00423-014-1221-7 (2014).

40. Lin, I.-C., Lee, C.-C. \& Liao, S.-L. Assessing quality of life in Taiwanese patients with Graves'ophthalmopathy. J. Formos. Med. Assoc. 114, 1047-1054. https://doi.org/10.1016/j.jfma.2013.12.002 (2015).

41. Stanislawska-Kubiak, M., Warchol-Biedermann, K., Skommer, M., Mojs, E. \& Wojciak, R. W. The role of intra-and interpersonal relations in the process of diagnosis and treatment. J. Med. Sci. 88, 156-162. https://doi.org/10.20883/jms.323 (2019).

\section{Author contributions}

N.S.-G., K.W., and P.Z designed the study, were involved in data collection, analyzed data, and wrote and revised the manuscript. S.S., A.C.Z., and W.W. collected data and were involved in data analysis. J.S. and E.S.-P. were involved in data analysis and revised the paper. M.R. revised the paper. All authors edited and approved the final version of the manuscript.

\section{Competing interests}

The authors declare no competing interests.

\section{Additional information}

Correspondence and requests for materials should be addressed to N.S.-G.

Reprints and permissions information is available at www.nature.com/reprints.

Publisher's note Springer Nature remains neutral with regard to jurisdictional claims in published maps and institutional affiliations.

Open Access This article is licensed under a Creative Commons Attribution 4.0 International License, which permits use, sharing, adaptation, distribution and reproduction in any medium or format, as long as you give appropriate credit to the original author(s) and the source, provide a link to the Creative Commons licence, and indicate if changes were made. The images or other third party material in this article are included in the article's Creative Commons licence, unless indicated otherwise in a credit line to the material. If material is not included in the article's Creative Commons licence and your intended use is not permitted by statutory regulation or exceeds the permitted use, you will need to obtain permission directly from the copyright holder. To view a copy of this licence, visit http://creativecommons.org/licenses/by/4.0/.

(C) The Author(s) 2021 